\title{
The Importance of Communicating Psychological Concepts in Educational Contexts: a Portuguese Exhibition
}

\author{
Sara Bahia $\mathrm{a}^{\mathrm{a}^{*}}$, João Nogueira ${ }^{\mathrm{b}}$ \\ ${ }^{a}$ University of Lisbon, Lisboa, Portugal \\ ${ }^{b}$ New University of Lisbon, Lisboa, Portugal \\ *Corresponding author. E-mail:sarabahias@gmail.com
}

Background. The principles of acquiring knowledge and developmental theories are powerful tools that psychologists use in educational contexts to change people's lives. As student populations become more diverse, psychologists need to play an important role in the evaluation and adaptation of their cognitive, behavioral, motivational, attitudinal, and emotional needs and challenges. They can intervene in various areas, from curriculum development, to regulations and guidelines for the application of direct educational tools and techniques by students, teachers, or institutions. One way to promote change at a macro-level is through providing creative experiences, such as interactive and engaging exhibitions that foster personal development at different levels.

Objective. The main focus of this study was to contribute to a theoretical foundation for the need to communicate psychological concepts through exhibitions. The secondary focus was the feedback given by visitors of all ages and educational contexts about how they enriched their knowledge about emotions through participating in an exhibit on the subject.

Design. We used a descriptive design, which employed diverse kinds of feedback from the visitors to an exhibition to measure its impact. The exhibition aimed at explaining in an interactive way what emotions are and how they may be regulated. The Southern Regional Delegation of the Order of Portuguese Psychologists (OPP) developed and displayed the "Experiencing Emotions" Exhibition (EEE), which featured 30 different activities divided into three parts: recognizing, living with, and transforming emotions. The exhibition toured the southern region of Portugal for nine months and was visited by more than 9000 people.

Results. The feedback was positive for all indicators.

Conclusion. Exhibitions like this one may be powerful instruments in the future to ensure that everyone has access to psychological concepts through interactive experiences, and gains knowledge about themselves, others, and the world.
Keywords: education of the emotions; museology and psychology exhibitions; emotions meaning-making; educational interventions in museums; professional psychology; Experiencing Emotions Exhibit 


\section{Introduction}

Psychology as a profession aims to change the lives of people and groups. Using its own scientific foundation for understanding people and their problems, its mission is to promote well-being by changing patterns of thought and behavior (e.g., MacKay, 2008). Change is constant, and, ultimately, the society we live in is the product of numerous changes of paradigms that in turn have led to different values, beliefs, and ideas about reality (Ricou, Cordeiro, Franco, \& Costa-Lobo, 2018). In a changing world, in which people are constantly confronted with new choices, psychology faces novel challenges in explaining and predicting the form and nature of rapid societal changes (Smith, Livingstone, \& Thomas, 2019). This may be one of the reasons why psychology was identified by Boyack, Klavans, and Börner (2005) as one of the "hub" sciences. Along with mathematics, physics, chemistry, the earth sciences, medicine, and social sciences generally, psychology is one of the most central and influential academic disciplines.

\section{Directions of change in psychology}

In a decade where science recognizes the need for a paradigm shift, psychology faces the huge challenge of re-conceptualizing its foundations. Teo (2015) stresses that psychology must critically redefine the relationship between individual subjectivity and society, the importance of reflexivity, and the ethical-political positions that underlie psychological research and practice in different contexts. Rethinking psychological approaches means, on one hand, considering people as in motion and, on the other, knowledge as constant change. These considerations make it impossible to perceive people out of the context of their surrounding world (Chiari, 2019). Systemic approaches are, thus, a requisite for psychological research and practices.

New concepts in psychology have emerged due to the application of quantum principles for modeling cognition and have enabled the use of novel conceptual tools (Pothos \& Busemeyer, 2013). Rosenmann, Reese, and Cameron (2016) consider globalization the defining feature of contemporary social life, and emphasize the interconnectedness of societies, economies, and cultures. Globalization is seen as a multifaceted process with a psychological impact on identity, that opens up possibilities for social change through the application of psychological science to the study of complex issues (Rosenmann et al., 2016). Increasingly diverse populations inevitably result from globalization (Edge \& Lemetyinen, 2019). In a society that induces a worldwide paradigm shift at all levels, Ferguson (2019) recommends that psychological science embrace change, openness, and transparency, and Teo (2011) advocates challenging the status quo and myths.

Curiously, museums and exhibitions are currently reflecting this conceptual change. Many exhibitions are being created not just for passive viewing, but rather for a readjustment of how visitors understand knowledge or theories (Schreiber, Pekarik, Hanemann, Doering, \& Lee, 2013). Such exhibitions also aim to promote the acquisition of cultural competence, which, according to Edge and Lemetyinen (2019), enhances the ability of practitioners to work with a range of individuals with whom they might have little in common. Ultimately, psychology is about supporting and empowering others, and that is why psychologists promote their 
clients' autonomy and self-determination and respect their individual differences from a perspective of "unequal equality" (OPP, 2011, p. 14).

Psychology grasps subjectivity in all of its modes of expression. It studies behaviors, and the behaviors that inhibit or increase them; experiences, as well as the experiences that motivate or hinder subjective expressions; and consciousness, and the awareness that reveals or disguises it (Giorgi, 2013). This is why psychology is complex. Subjectivity is at the heart of psychology, and phenomenological approaches seem to be authentic modes of grasping it. Change is made possible by fostering critical thinking and internalizing the theoretical and practical tools that allow psychologists to work with people and communities who suffer (Teo, 2015).

\section{New horizons for psychologists in educational contexts}

The core of education is an explicit view of the future and of the resources needed to acquire an adequate engagement with the world (Claxton \& Lucas, 2016). Irrevocably, education and its direction are about values (Biesta, 2015). However, today's educational practices may be irrelevant, and even damaging (e.g., Claxton \& Lucas, 2016). In this sense, psychology ought to be focusing its efforts and resources on addressing these key concerns by proclaiming its discoveries and possibilities, and shifting to values and priorities that lead to true change.

According to Buck (2015), psychological approaches address diverse issues and needs, and build on different frameworks such as humanistic, phenomenological, solution-oriented, problem-solving, constructivist, executive, systemic, and integrative frameworks. Global systemic frameworks are relatively content-free and help psychologists manage the increasing complexities. Integrating frameworks provide important contributions to the larger field of lifespan development and may establish an alternative to risk- and problem-focused models (Tolan, Ross, Arkin, Godine, \& Clark, 2016). This is what psychologists who work in educational contexts do: that is, they use their comprehensive psychological knowledge to promote the welfare of different people and communities.

Psychologists who work in education as practitioners or researchers have a powerful role to play in this important process (Claxton \& Lucas, 2016). Gibbs (2018) emphasizes that the role of psychology in education is to help others become human and help people learn to be more human, in the same way that William James questioned the types of human abilities that existed in his time, - and how they could be unleashed, over a century ago (James, 1890). In an increasingly diverse world, a culturally imaginative educational psychology is urgently needed (King, McInerney, Dennis, \& Pitliya, 2018). An innovative and imaginative contribution to meeting the challenges needed to make a bigger impact in society, may be to show different people in different contexts some of the concepts all psychologists work with on a daily basis, so as to impact people's knowledge and development, the two core theoretical backgrounds of educational psychology.

Based on the ideas that behavior is an experiment and knowledge is doing, Chiari (2016) goes even further and states that living is knowing and knowing is changing. Both Piaget (1971) and Vygotsky (1978) stressed the importance of cultural activities in the development of symbolic thought and mental operations, as 
well as of personal and social adaptation. Meaning is created through an interaction of the interpreter and the interpreted. Meaning does not exist objectively in the world as something to be discovered, but is actively created through human engagement and collaboration.

Falk and Dierking (2012) explain how people learn about and from the environment, namely through artefacts in museums, or exhibition tasks, and thus construct meanings about, and within, cultures. Their model refers to the physical, sociocultural, and personal contexts which give meaning in the course of the visits and the subsequent learning processes and their outcomes. This constructionist epistemology has broadened our knowledge of meaning-making, a process explained by activity theory, which breaks it down into a series of concepts such as internalization and externalization, tool mediation, motives, goals, activities, actions, and operations (e.g., Kaptelinin \& Nardi, 2017).

Undoubtedly, some experiences promote meaning-making that has a longterm impact on people's lives. Exhibitions designed to engage visitors for self-education on a subject inspire their visitors to learn more (Leister, Tjøstheim, Joryd, de Brisis, Lauritzsen, \& Reisæter, 2017). Furthermore, investing in the development of creative and critical thinking will determine the way future generations cope with contemporary challenges, and generate experiences that may internalize such competencies (Bahia \& Trindade, 2014).

The main focus of our study was to contribute to a theoretical foundation for the need to communicate psychological concepts through exhibitions. The secondary focus was a discussion of the feedback given by visitors of all ages and educational contexts about how they enriched their knowledge on emotions through the exhibitions.

\section{Method}

The design of this study was descriptive, using all the feedback obtained from the visitors of the "Experiencing Emotions" exhibition, which toured southern Portugal in 2017 and 2018.

\section{Participants}

Approximately 9000 people visited the exhibition over a nine-month period. The exhibition travelled throughout southern Portugal and stayed for one or two weeks in 12 different institutions at the request of the psychologists who worked there. Of the 12 institutions visited, three belonged to a municipality (library, fire-headquarters, or social association); one was a community center for pre-school children and the elderly; one was a cultural center; and the other seven were educational institutions from pre-school to higher education (four private schools, two public schools, and one university faculty). Visitors' ages ranged from three to 90 . The older visitors came from community, social, and cultural associations and centers. The cultural, ethnic, and social background of the visitors was diverse. The majority lived in underprivileged urban areas and were Caucasian.

The visits were guided by the 12 psychologists who had requested the exhibition. Approximately 6000 people explored the exhibition using the authors' guidelines. However, according to the janitors and security staff who controlled the entrance 
to the exhibition at the institutions that were open to the public, 3000 additional people explored it freely; the majority of these people were either families who were picking up their children, or the local staff of the institutions. Of the total visitors, approximately $30 \%$ were adults, $40 \%$ aged 10 to 20 , and $30 \%$ aged 3 to 10 . Over 300 visitors had special needs (visual, cognitive, and/or physical).

\section{Instruments}

Exhibition creators want their messages and narratives to be understood and want to understand their impact on visitors who have different preferences for how they look at and act on their experiences (Schreiber et al., 2013). Understanding what visitors understand and do, and why, is the aim of assessments of the impact of visits to museums or exhibitions, which are done through specific profiles and studies (e.g., Leister et al., 2017). Schawn and colleagues (2014) advocate that such evaluations include the physical, sociocultural, and personal contexts of the spaces and the people involved in the exhibitions. All these dimensions were included in the evaluation of the impact of this exhibition, both on visitors and on the psychologists who worked on it.

The main instrument used at the closing of each exhibition tour was a grid proposed by Bahia \& Janeiro (2008) called the Efficacy Evaluation of Educational Interventions in Museums (EEEIM), which was filled in by the psychologists who worked with visitors after all the different visits were made. This grid was constructed on the basis of an eclectic theoretical frame of reference, drawing on behavioral, cognitive, constructivist, systemic, and ecological theoretical models which specified the main categories of evaluation of the effectiveness of exhibitions and other non-formal interventions. The two main categories of the grid were the evaluation of the process and the evaluation of the results. Only this last part was used. It concerned the visitors', psychologists', and monitors' behaviors and opinions pertaining to cognitive, motivational, affective, social, and moral levels of analysis. The grid included a space to record the perception of the efficacy of a specific visit using a Likert-type rating scale from 1 to 7 ( 1 meaning completely absent and 7 entirely present), as well as a space for the recording of concrete examples.

Additional data on the impact of the visit was gathered through interviews, narratives, statements from the visitors and psychologists, and the results were subjected to an inductive content analysis. A semi-structured interview aimed at complementing all the answers in Bahia and Janeiro's EEEIM grid. The main questions focused on the specific impact of the visit and included what kind of knowledge the visitors gained after the visit; which tasks were more or less engaging; and the impact the visit had over the following days, or even weeks and months. The interviews were carried out by all 12 psychologists responsible for the visits, as well as by the 12 monitors who guided visitors. The first author also interviewed 30 visitors in several locations of EEE, and seven teachers from two schools. One of the school psychologists authored a questionnaire that was also used by two colleagues. The questionnaire was answered by five hundred 12 to 19-year-old students and focused on their overall appreciation of the exhibition, the most and the least interesting tasks, and the impact of the visit. At nine institutions, visitors were invited to write down their opinions about the visit. A total of 85 visitors wrote general comments. 


\section{The Exhibition "Experiencing Emotions"}

With the purpose of consolidating the relevance of psychology in Portugal, the Southern Regional Delegation of the Order of Portuguese Psychologists promoted a traveling exhibition entitled "Experiencing Emotions" (EEE) for nine months. The exhibition aimed to show the population in several municipalities of this region the importance of psychologists for their daily lives. More specifically, the EEE

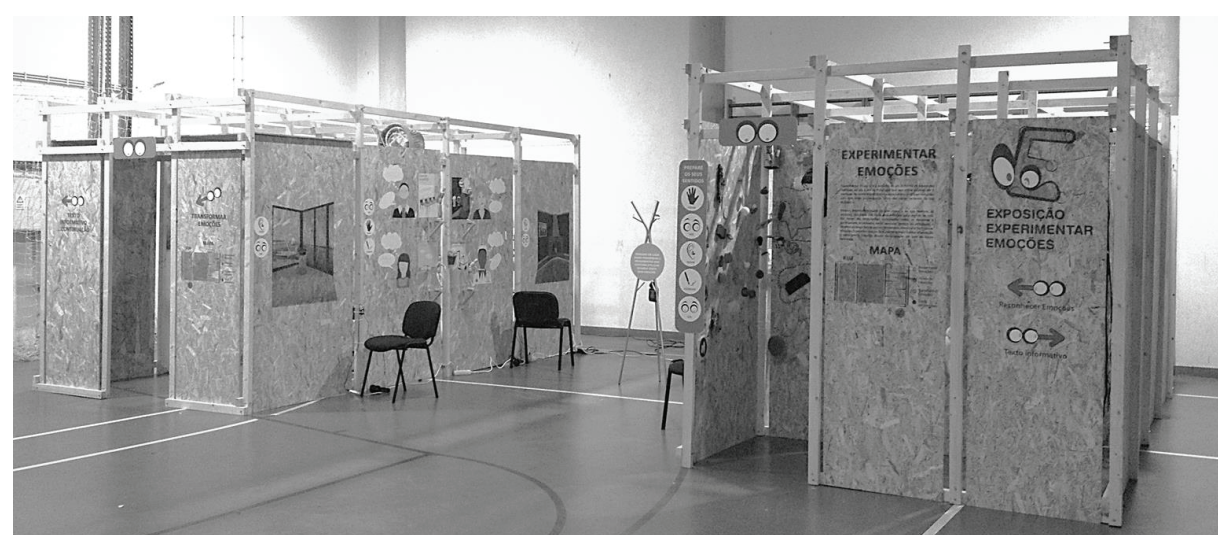

Figure 1. Overview of the EEE set-up

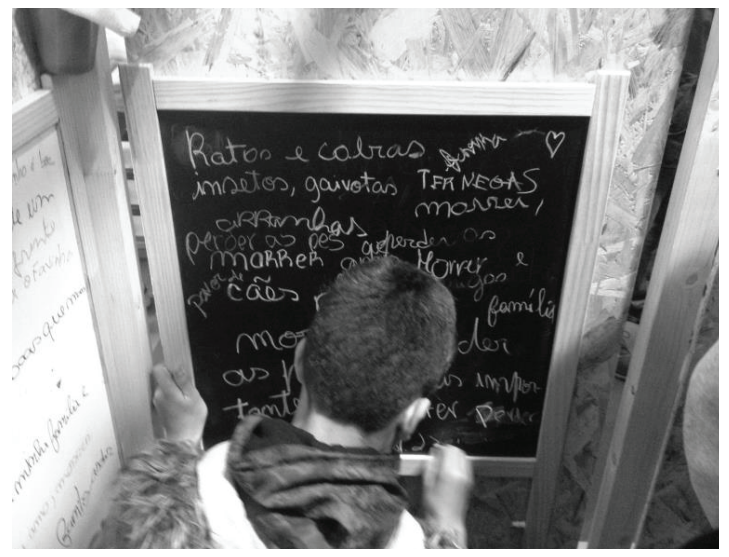

Figure 2. A visitor writing about fears

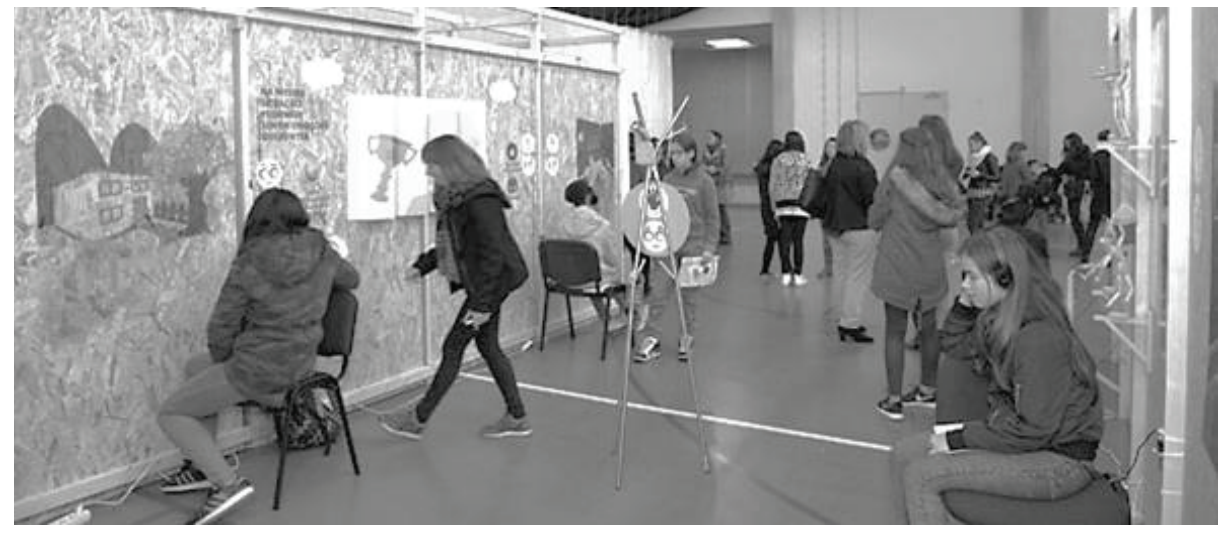

Figure 3. Visiting "Living Emotions" 
presented, in a dynamic and interactive way, one of the main concepts that psychologists deal with in their work, namely, emotions (see Figures 1 to 3).

The visitors were asked to recognize emotions, to understand the different contexts in which they arise and how they affect thoughts and behaviors, and to explore ways of transforming them.

Recent perspectives on exhibitions see them as more theme-centered and less object-oriented - that is, arising from collective memories and from contemporary needs. In fact, psychology catches subjectivity in all of its modes of expression (Giorgi, 2013) and must therefore continuously redefine the relationship between individual subjectivity and society (Teo, 2015). Naturally, emotions emerge as an encompassing and critical theme of interest not only to psychologists, but also to everyone else. The exhibition intended to foster alternative representations on emotions (e.g., Tolan et al., 2016) and focused on ways of working with diversity and difference (e.g., Edge \& Lemetyinen, 2019). That is why the team was composed of psychologists representing different theoretical models and fields of practice.

The EEE was conceived by a group of 10 psychologists: Ana Meira, David Guedes, Inês Martins, Inês Reis, Luísa Mota, Maria Ana Jaillet, Maria Teresa Martins, Paulo Mota Marques, Tiago Lopes Lino, and coordinator Sara Bahia. Their ages ranged from the early 20s to nearly 60 . Having between one and 36 years of experience, these psychologists had worked in clinical, educational, and organizational contexts in different regions of southern Portugal, and belonged to different schools of thought: dynamic, systemic, constructivist, cognitivebehavioral, integrated, humanistic, phenomenological, solution-oriented, and problem-solving. We agree with Buck's view (2015) that various psychological approaches address diverse issues and needs of people, and build on different frameworks.

Beatriz Berger was the graphic designer and illustrator, and Tiago Farinha conceived the wooden structures that displayed the objects of the exhibition. David Guedes, who won the prize of best national junior psychologist for his internship at a non-profit charity organization, wrote the text displayed on the exterior walls of the exhibition and printed on a pamphlet, which visitors could take home. Guedes' (2016) manuscript, which was given to all visitors, highlighted in an accessible manner the main theoretical frameworks and psychological interventions on emotions.

The ultimate goal of exhibitions is to generate change in specific patterns of thought and behavior, as MacKay (2008) has suggested, or even to modify to some extent values, beliefs, and ideas about reality (e.g., Ricou et al., 2018). The present exhibition had two main targets: on one hand, different populations in singular contexts and from various backgrounds; on the other hand, psychologists from different fields of practice and with different experiences, some of whom had few opportunities for sharing perspectives with colleagues due to their geographical locations. One of the main missions of the Southern Delegation of the OPP is precisely to fight against the isolation experienced by some psychologists and the populations they work with, and support and empower people to be autonomous and self- 
determined (OPP, 2011). According to Edge and Lemetyinen (2019), psychologists who acquire broad cultural competence adapt their interventions and may transform the lives of more people. Internalizing theoretical and practical tools allows them to work with the different people and communities that are confronted with power and injustice (Teo, 2015). In this sense, the exhibition attempted to provide an opportunity to mobilize communities, and the psychologists who work with them, to discuss and acknowledge the importance of emotions in all their daily activities.

Many exhibitions today feature a series of dynamic events in which symbolic processes create meaning (Hooper-Greenhill, 2000) and redefine values and beliefs (e.g., Duncan, 2005). Research shows that the more dynamic and interactive the exhibitions are, the more effective they are in creating change. Interactive experiences have long been recognized as crucial for individual development (e.g., Piaget, 1971; Vygotsky, 1978). Active meaning-making engages and encourages interaction (e.g., Falk, Randoll, \& Dierking, 2012). That is why engaging exhibitions foster self-education and inspire learning (Leister et al., 2017), as well as creative, critical thinking and cooperation skills (e.g., Bahia \& Trindade, 2014). Visits to exhibitions provide meaningful learning experiences for all. Therefore, developing these kinds of projects offers opportunities to foster diverse communities and empower people (e.g., Wilson, Bryant, Reynolds, \& Lawson, 2015).

Multiple studies have revealed that these experiences are effective in many aspects of development. Schawn, Grajal, and Lewalter's (2014) analysis of museums, zoos, and other type of exhibitions illustrates the importance of an ecology of learning that also affects enjoyment, fun, curiosity, surprise, communication, and aesthetics, and which the authors define as promising areas of future educational research. These exhibitions are perceived as rewarding and usually encompass cognitive, introspective, objective, and social experiences. They are also a place where information can be exchanged before, during, and after the visit, and can be adapted to different types of visitors. For example, hands-on activities in museums develop diverse conversational styles in different children and are inspiring for parent-child communication (Callanan, Castañeda, Luce, \& Martin, 2017). Such visits may trigger other extended activities after the visits, such as reading, viewing documentaries, reading books, or experimenting (e.g., Alexander, Johnson, \& Kelley, 2012). Visitors frequently consider such exhibitions thought-provoking (e.g., Wilson et al., 2015). Careful integration of hands-on activities that echo and amplify the goals of more traditional exhibitions, encourages deeper communicational skills, thinking, and engagement in learning experiences (e.g., Callanan et al., 2017). Moreover, exhibitions do not only benefit visitors (Edge \& Lemetyinen, 2019). In this case, the EEE also intended to enrich psychologists and their work in different contexts, from schools to health care centers and organizations. Psychologists were able to revisit and broaden their knowledge of theoretical and practical frameworks on emotions, and also use an innovative approach to show their clients, colleagues, and communities a concept that is always present in their work. In sum, the mission of the exhibition was to inform and inspire visitors to explore the psychologi- 
cal dimensions of emotions, and to allow psychologists to enrich and communicate their knowledge and work on emotions.

No specific theoretical framework was chosen for the exhibition. Instead, the team's view was that the visitors - and psychologists - should explore what emotions are, and see them all as adaptive and essential to well-being. The EEE highlighted six emotions: joy, sadness, fear, disgust, anger, and surprise. The team engaged in a lively debate before deciding on these emotions and the activities that would be appropriate for all types of visitors. The 30 different activities of an interactive nature, could be explored individually or guided by a psychologist.

The activities were divided into three parts, and exhibited in three different spaces, specifically, in wooden cabins of 15 square meters each. The presentation of the information was both sequential and synchronized, and appealed to the use of all the senses, but mainly vision and touch, and to personalized interpretation of hands-on activities; it included listening to some narratives (e.g., Schawn et al., 2014). A compact guide was given to all visitors to facilitate the tour. Resources included headphones, manipulating various objects, and writing with markers on the walls, white boards, and post-its. The exhibition was conceived to be inclusive in the sense that the architectural structure was built to accommodate wheelchairs, and visitors with special needs could complete all the activities.

In the first part, Recognizing Emotions, visitors were invited to prepare their senses before entering and look for emotional clues during the four sections which were displayed sequentially in a maze (see Table 1).

Table 1

Activities of Part 1 - Recognizing Emotions

I. "Try-out" encouraged visitors to touch and smell objects, or look at different images and notice the thoughts, memories, and emotions they evoked. The last part of this first section was a walk through a maze of different textures.

II. "Identify and post-it!" where visitors had to stop and write on post-its all the emotions they had felt up to that moment of the visit.

III. "Cube of Fear," a dark empty cube which visitors entered. Afterwards they were invited to write what their greatest fear was on a big whiteboard or blackboard, entitled "The book of fear."

IV. “Think with your body" consisted of six different silhouettes painted on the wooden wall at the end of the maze. Each of them represented one of the six emotions depicted: joy, sadness, fear, disgust, anger, and surprise. Visitors had to draw the parts of the body in which they usually feel each emotion.

In the second part, Living Emotions, the activities encouraged visitors to explore different contexts in which we experience emotions, and discover how different ways of thinking about situations can elicit different feelings (see Table 2). 
Table 2

\section{Activities of Part 2 - Living Emotions}

I. "Listening to emotions" consisted of chairs being placed in front of four scenarios (schoolyard, girl's room, fireplace, and airport lounge) where visitors sat and listened on the headphones to the emotional narrative of actors impersonating a bullied pupil, a girl listening to her parents arguing, an unemployed father, and a businesswoman afraid of flying. The narratives were written by four clinical and educational psychologists, members of the team which organized the exhibition.

II. "A situation experienced with such different emotions!" asked visitors to observe the same picture from two different perspectives. In both images the boy is receiving a prize, but the emotion depicted is very different. Visitors had to identify what the possible emotions in both images were, and reflect on how winning can make us feel different emotions depending on how we look at the situation (as an achievement, a threat, a responsibility, or something undeserved?).

III. "Contextualizing emotions" communicated the idea that different contexts may elicit different thoughts, verbalizations, and postures. Visitors were requested to write on balloons different thoughts and narratives that an articulated wooden manikin in each context might be feeling, analyze the influences of emotions in behavior, and manipulate the manikin in order to express possible emotions.

IV. "Tree of emotions" encouraged visitors to match emotions and a set of popular proverbs or expressions, and think about the cultural biases that underlie such expressions.

The third space, Transforming Emotions, gave visitors different opportunities to feel, transform, communicate, and express different emotions (see Table 3).

Table 3

Activities of Part 3 - Transforming Emotions

I. "Emotional shadows" invited visitors to shape their bodies in front of the projector so that their shadow matched three silhouettes painted on the wall, which ranged from crouching on the floor to raising their arms in the air.

II. "Emotions transformation table" offered almost impossible games and puzzles that made visitors lose their patience, and then explained different ways of balancing emotions.

III. "Zigzag of transformations" consisted of a series of activities for visitors to try out different strategies to regulate their emotions. They were invited to externalize emotions through yelling their frustrations into a hole or scribbling on a whiteboard, phoning someone or hugging a huge teddy bear, rehearsing different expressions in front of the mirror and trying to modify the thoughts behind them, relaxing inside the canopy, distracting themselves with games, or simply accepting their own emotions.

Before leaving, visitors read a big board with the sentence: "Thank you for your visit, and remember that psychologists can help us deal with emotions!" An explanatory text on emotions (Guedes, 2016) was engraved on the external walls of the exhibition. 
Psychologists interested in showing the exhibition in their workplaces requested it by mail and were responsible for guiding the visits or ensuring individual visits. Each psychologist could explore the potential of the 30 activities, equally distributed through the three sections, and adapt them to the specific populations that visited.

\section{Data analysis}

Content analysis from the interviews with visitors and psychologists, questionnaires filled out by psychologists, narratives written after the visit by students, and statements written by the public during their visits were the data. It is important to note that the results pertain only to the data collected from these instruments. Two visits were not recorded by the psychologists, and in the places where visits were not guided, the only record was of the number of visitors noted by the security guard of the building where the exhibit was housed. Thus, the final number of visitors studied amounted to approximately 5000.

\section{Results}

The results of the impact of the Exhibition Experiencing Emotions are presented in accordance with Schawn and colleagues' (2014) categorization and Bahia and Janeiro's observational grid (2008).

In terms of the physical context, the exhibition was considered by both the psychologists and visitors as well-organized and with an easy orientation. All the people interviewed commented that the architecture and design of the exhibition was appealing and appropriate to the expression of emotions. In all locations, the atmosphere of the exhibition created interest and surprise. The ambience during the visits aroused curiosity, smiles, and laughter in all three spaces.

The sociocultural context considers the mediation with the visitors. In this case, the visits lasted between 30 and 50 minutes, and the majority of them were guided. However, the tasks required a personalized interpretation. Groups of 8 to 12 visitors entered the first space where objects and tasks were presented in a maze in which only two people could wander side by side. The information was presented visually through drawings, signs, or short sentences with particular relevance to the hands-on activities and was considered very attractive and thought-provoking, in consonance with the view of Ali, Koleva, Bedwell, and Benford (2018), who found that physical placement and aesthetic content ensure effective shaping experiences. Most of the information across the space was available simultaneously, - and was acquired on the move.

The space where visitors remained the longest was "Transforming Emotions." The most appreciated was "Zigzag of Transformations," but curiously, the least executed task was "Emotional shadows." In all places both adolescent and adult visitors were embarrassed to exercise their bodies and make their shadow overlap the silhouettes painted on the walls. Children were less shy, but did not take promptly to the task. Some psychologists and other monitors interviewed thought that this was due to a cultural problem: tasks involving body movement are not very common in public spaces. 
In terms of the personal context, the sample was varied in terms of age, background, prerequisites, prior knowledge, and interests. Different motives led people to visit, ranging from school trips to a neighbor's suggestion. Expectations also varied: from an opportunity to learn part of a school subject to the belief that there is nothing more to learn, as two of the elderly groups expressed it. The beliefs of the visitors were also diverse, but all assumed the visit would be interesting, useful, and thought-provoking.

Table 4

Competencies acquired in the twelve visits to the Exhibition

\begin{tabular}{|c|c|c|c|}
\hline Level & Competencies & Mean & Examples \\
\hline \multirow{4}{*}{ Cognitive } & $\begin{array}{l}\text { Specific knowledge } \\
\text { acquired }\end{array}$ & 5.3 & $\begin{array}{l}\text { "Emotions are more adaptive than } \\
\text { I thought". (senior man) }\end{array}$ \\
\hline & $\begin{array}{l}\text { Problem solving } \\
\text { processes }\end{array}$ & 4.5 & $\begin{array}{l}\text { "The boy holding the trophy is sad because } \\
\text { winning makes him more competitive" } \\
\text { (written on the board by an adult). "I feel } \\
\text { fear in my tummy and my colleague feels it } \\
\text { in her throat". (12-year-old boy). }\end{array}$ \\
\hline & Critical analysis skills & 4 & $\begin{array}{l}\text { "I now understand my father's feelings." } \\
\text { (15-year-old boy) }\end{array}$ \\
\hline & $\begin{array}{l}\text { Presentation of innovative } \\
\text { and creative solutions }\end{array}$ & 4.1 & $\begin{array}{l}\text { "Scribbling is a good way of externalizing } \\
\text { my anger towards ..." (10-year-old girl) }\end{array}$ \\
\hline \multirow[b]{2}{*}{$\begin{array}{l}\text { Motiva- } \\
\text { tional }\end{array}$} & Time of participation & 6.2 & $90 \%$ were attentive and engaged \\
\hline & Task involvement & 6.4 & $\begin{array}{l}\text { More than } 90 \% \text { of the visitors were actively } \\
\text { involved in questioning and explaining. The } \\
\text { least engaged were the senior visitors. }\end{array}$ \\
\hline \multirow{3}{*}{ Affective } & Emotional expression & 5.8 & $\begin{array}{l}\text { "Her body shows melancholy." (13-year-old } \\
\text { girl) }\end{array}$ \\
\hline & Aesthetic sensibility & 4.5 & $\begin{array}{l}\text { "The drawings of each emotion are very ex- } \\
\text { pressive." (psychologist) }\end{array}$ \\
\hline & General appreciation & 6.1 & $\begin{array}{l}\text { "The exhibition has changed the way I think } \\
\text { about emotions." (senior visit } 4 \text { months after } \\
\text { the visit) }\end{array}$ \\
\hline \multirow{4}{*}{ Social } & Social skills & 4.5 & Frequent interactions \\
\hline & Collaboration skills & 4.3 & $\begin{array}{l}\text { Help others find solutions. Discussing per- } \\
\text { spectives }\end{array}$ \\
\hline & Communication skills & 4.2 & $\begin{array}{l}\text { Nearly all visitors spoke and half of them } \\
\text { wrote. }\end{array}$ \\
\hline & Acceptance of diversity & 4.1 & $\begin{array}{l}\text { "I hope people can control their emotions } \\
\text { more frequently!" (16-year-old boy) }\end{array}$ \\
\hline \multirow{3}{*}{ Moral } & Attitudes & 5.6 & Surprise, cooperation \\
\hline & Values & 5.1 & General respect for the exhibition \\
\hline & Ethical concerns & 4.5 & $\begin{array}{l}\text { "I wish we could respect everyone's feelings." } \\
\text { (10-year-old girl) }\end{array}$ \\
\hline
\end{tabular}

Scale: From 1 (minimum) to 7 (maximum) 
The main results of the responses of the 10 psychologists to the EEEIM grid are summarized in Table 4. The global result is an average of nearly 5 points out of 7 (4.95) for the totality of dimensions measured, which can be interpreted as a positive indicator.

The analysis of the post-its written by the visitors in the second "Identify and post-it!" revealed that $78 \%(\mathrm{~N}=5102$ of a total of 6541$)$ of the contents referred to the primary emotion of happiness. Fear, surprise, and disgust were also mentioned. Distress and sadness due to sad remembrances were mentioned by $2 \%(\mathrm{~N}=39)$ of the adults.

Using the records of the psychologists who provided information and the photographs taken after visits, the body parts most identified as being the part where each person felt a specific emotion are in Table 5.

Table 5

"Think with your body"

\begin{tabular}{ll}
\hline joy & head, heart \\
sadness & tummy, head \\
fear & legs, stomach \\
disgust & head, hands \\
anger & forehead, ears, chest \\
surprise & hands, mouth \\
\hline
\end{tabular}

The thoughts and verbalizations varied according to the context. For instance, there were 10 instances of the greatest fear being "being caught and going to prison" in a school in a neighborhood where many thefts occur. However, the most relevant result mentioned by the psychologists and monitors in the interviews, was that thinking about the possible thoughts underlying the expression of emotions was challenging and motivating. Three psychologists mentioned that this was the most effective activity.

Three main categories emerged from the interviews with the psychologists and monitors: deeper knowledge, change in behavior, and emotional reflection (on self and others). In the schools where the exhibition was displayed, teachers told the psychologists that they noticed the pupils (ages between 3 to 18) expressed more emotions verbally in the days following their visit. Another indicator was the wide attention span and engagement, both in schools, where students behaved better than usual, and in the other contexts. Visitors recognized that they had learned more about emotions, what they are, how they affect people's lives, and how they can be changed. Moreover, the psychologists, and also some teachers, considered the exhibition a starting point and further engaged in activities to develop the theme. But maybe the most interesting and unexpected result was that six psychologists reported that some visitors still spoke about the contents of the exhibition one or two years later. 


\section{Discussion}

The main aim of the exhibition was to make people recognize that emotions are essential for their adaptation, and that this awareness can change their lives. That is what the team who conceived it intended to achieve. In all the activities, the key idea that the Exhibition Experiencing Emotions had in mind was that knowing is changing. To some extent we may say that the visit to the EEE changed the way visitors looked at emotions. However, we cannot draw this conclusion because the evaluation was not systematic, due to the huge number of visitors and the nature of the exhibition. Nonetheless, we can be sure that this exhibition was a modest contribution to people rethinking alternative practices of psychology by proclaiming its discoveries and possibilities (e.g., Smith et al., 2019), facilitating its application to the study of problems (e.g., Rosenmann et al., 2016), and incentivizing debates (e.g., Pothos \& Busemeyer, 2013).

Providing people with an opportunity to use tools and experiment hands-on (e.g., Kaptelinin \& Nardi, 2017) and exchange information before, during, and after the visit (e.g., Callanan et al., 2017) constituted an alternative to the way psychology is traditionally seen in Portugal. Visiting exhibitions offer added value to the creation of meaningful learning experiences in varied contexts (Clark, Ashbrooke, \& Price, 2019). Furthermore, as Schreiber and colleagues (2013) state, exhibitions provide an opportunity for people to readjust their understanding of a piece of knowledge or theories. That unquestionably happened with the psychologists of the team and the ones who worked with the exhibition. In order to be truly transformative, psychology should consider taking up the systemic practices that enable more people to benefit from its concepts.

Further ideas were developed in each institution. For example, some psychologists a developed a leaflet of activity suggestions for teachers after the visit to the exhibition. The exhibition was explored as a useful instrument for psychologists in these contexts and turned out to be a powerful vehicle to deepen knowledge and reflection on emotions.

In school contexts, the psychologists had the opportunity to develop activities related to each part of the exhibition. After the first part ("Recognizing emotions") psychologists engaged groups and individual students of different ages in reflecting on different emotional states caused by situations in daily life. These included analyzing people's feelings, such as fear; showing how they can benefit from their mistakes; discovering abstract words that express emotions and ways to apply them; understanding other senses of words and expressions and matching them to different images; finding ambiguous or metaphorical emotional expressions; or using long written or oral texts with emotional vocabulary.

"Living emotions" was the motto for working with people who live with emotionally challenging experiences, to develop creative associative writing; analyze proverbs and quotes about emotions; examine, debate, and act out situations that require emotional control solve emotional dilemmas; and observe and analyze the emotions displayed in the functioning of social groups.

The tasks developed to work on the contents of the third part ("Transforming emotions") included finding multiple solutions to transforming emotions and analyzing their viability; deliberate training of dexterity and motor coordination in an 
effort to express sequences of emotions; making shadows with the body, arms, or fingers to express different emotional states; verbalization or dramatization of situations that lead to different emotional tonalities; and the simulation of situations of emotional persuasion.

These are some examples of how psychologists who work in educational contexts may use these kinds of exhibitions to promote many opportunities for change. Both the solid and thorough theoretical foundation of the exhibition, as well as the activities suggested, motivated the psychologists to further explore the theme in much more active and interactive ways than they would have if they had not had access to the exhibition. In this sense this exhibition was inspiring to all its users.

Although psychologists recognize their field of theory and practice as being of utmost importance in promoting a better life in this changing world, society is far from acknowledging that potential of the role of psychology and psychologists. That is the situation which this exhibition attempted to remedy. The results showed that the exhibition promoted a deeper knowledge of emotions, as well as behavioral changes and emotional reflection about self and others. The attention span and engagement during the visits motivated involvement in the further activities conceived to develop the exhibition's theme and led to a deeper understanding of what emotions are, how they affect people's lives, and how they can be changed.

Another unexpected result was the follow-up one and two years after the exhibition. Six psychologists emailed the Order to inform us that one year later, visitors still spoke about the contents of the exhibition, and two repeated the same content two years later, revealing that exhibitions like this one may be powerful instruments to help people learn to be human, as Gibbs (2018) proposes. It is an imaginative way to make a large impact on society by showing people in different contexts what psychological concepts are, and how they may impact people's learning and development, thus ultimately promoting the welfare of different people and communities.

From the data gathered, the exhibition touched the lives of thousands of visitors, and hopefully was able to positively influence some of them.

\section{References}

Alexander, J.M., Johnson, K.E., \& Kelley, K. (2012). Longitudinal analysis of the relations between opportunities to learn about science and the development of interests related to science. Science Education, 96(5), 763-786. https://doi.org/10.1002/sce.21018

Ali, S., Koleva, B., Bedwell, B., \& Benford, S. (2018). Deepening visitor engagement with museum exhibits through hand-crafted visual markers. In I. Koskinen, Y. Lim, T. Cerratto-Pargman, K.Chow, \& W. Odom (Eds.), Proceedings of the 2018 Designing Interactive Systems Conference (pp. 523-534). New York: ACM. https://doi:10.1145/3196709.3196786

Bahia, S., \& Janeiro, I. (2008). Avaliação da eficácia das intervenções educacionais em museus: Uma proposta teórica. International Journal of Developmental and Educational Psychology, 1(3), 35-42.

Bahia, S., \& Trindade, J.P. (2014). Criatividade, cooperação e pensamento crítico: um exemplo em contexto de educação não formal. Revista Amazônica, 14(1), 300-324.

Bertrando, P., \& Arcelloni, T. (2014). Emotions in the practice of systemic therapy. Australian \& New Zealand Journal of Family Therapy, 35(2), 123-135. https://doi.org/10.1002/anzf.1051 
Biesta, G. (2015). Teaching, teacher education, and the humanities: Reconsidering education as a Geisteswissenschaft. Educational Theory, 65(6), 665-679. https://doi.org/10.1111/edth.12141

Boyack, K.W., Klavans, R., \& Börner, K. (2005). Mapping the backbone of science. Scientometrics, 64, 351-374. https://doi.org/10.1007/s11192-005-0255-6

Buck, D. (2015). Reconstructing educational psychology reports: an historic opportunity to change educational psychologists' advice? Educational Psychology in Practice, 31(3), 221-234. https://doi.org/10.1080/02667363.2015.1030724

Callanan, M.A., Castañeda, C.L., Luce, M.R., \& Martin, J.L. (2017). Family science talk in museums: Predicting children's engagement from variations in talk and activity. Child Development, 88(5), 1492-1504. https://doi.org/10.1111/cdev.12886

Chiari, G. (2016). To live is to know, to know is to change: Change in personal construct psychology and psychological constructivism. Journal of Constructivist Psychology, 29, 340-356. https://doi.org/10.1080/10720537.2015.1134364

Clark, Z., Ashbrooke, L., \& Price, J. (2019). Creating meaningful learning for children's nursing students: Can museum field trips offer added value? Comprehensive Child and Adolescent Nursing, 42(1), 71-84. https://doi.org/10.1080/24694193.2017.1390008

Claxton, G., \& Lucas, B. (2016). The hole in the heart of education (and the role of psychology in addressing it). Educational Psychology Review, 40(1), 4-12.

Duncan, C. (2005). Civilizing rituals: Inside public art museums. London: Routledge. https://doi.org/10.4324/9780203978719

Edge, D., \& Lemetyinen, H. (2019). Psychology across cultures: Challenges and opportunities. Psychology and Psychotherapy: Theory, Research and Practice, 92(2), 261-276. https://doi.org/10.1111/papt.12229

Falk, J.H., Randol, S., \& Dierking, L.D. (2012). Mapping the informal science education landscape: An exploratory study. Public Understanding of Science, 21(7), 865-874. https://doi.org/10.1177/0963662510393606

Ferguson, C.J. (2019). Embrace the unknown. The Psychologist, 32, 46-49.

Gibbs, S. (2018). The immorality of education: A position paper for educational psychologists. Educational \& Child Psychology, 35(3), 86-96.

Giorgi, A. (2013). Reflections on the status and direction of psychology: An external historical perspective. Journal of Phenomenological Psychology, 44(2), 244-261. https://doi.org/10.1163/15691624-12341257

Guedes, D. (2016). Experimentar emoções: Texto informativo. Lisboa: Ordem dos Psicólogos Portugueses/Delegação Regional Sul.

Hooper-Greenhill, E. (2000). Changing values in the art museum: Rethinking communication and learning. International Journal of Heritage Studies, 6(1), 9-31. https://doi.org/10.1080/135272500363715

James, W. (1890). The principles of psychology. New York: H. Holt \& Co. https://doi.org/10.1037/10538-000

Kaptelinin, V., \& Nardi, B. (2017). Activity theory as a framework for humantechnology interaction research. Mind, Culture, and Activity, 25(1), 3-5. https://doi.org/10.1080/10749039.2017.1393089

King, R.B., McInerney, D.M., \& Pitliya, R.J. (2018). Envisioning a culturally imaginative educational psychology. Educational Psychology Review, 30(3), 1031-1065. https://doi.org/10.1007/s10648-018-9440-z

Leister, W., Tjøstheim, I., Joryd, G., de Brisis, M., Lauritzsen, S., \& Reisæter, S. (2017). An evaluation-driven design process for exhibitions. Multimodal Technologies and Interaction, 1(4), 25. https://doi.org/10.3390/mti1040025

MacKay, T. (2008). Can psychology change the world? The Psychologist, 21(11), 928-931.

OPP (2011). Código deontológico da Ordem dos Psicólogos Portugueses. Lisboa: Ordem dos Psicólogos Portugueses.

Piaget, J. (1971). Biology and knowledge: An essay on the relation between organic regulations and cognitive processes. Chicago: University of Chicago. 
Pothos, E.M., \& Busemeyer, J.R. (2013). Can quantum probability provide a new direction for cognitive modeling? Behavioral and Brain Sciences, 36(3), 255-274. https://doi.org/10.1017/S0140525X12003226

Ricou, M., Cordeiro, S.A., Franco, A., \& Lobo, C.C. (2018). The identity of psychology. The Psychologist: Practice \& Research Journal, 1(1), 2-15. Retrieved from https://www.researchgate.net/publication/325858244_The_Identity_of_Psychology

Rosenmann, A., Reese, G., \& Cameron, J.E. (2016). Social identities in a globalized world: Challenges and opportunities for collective action. Perspectives on Psychological Science, 11(2), 202-221. https://doi.org/10.1177/1745691615621272

Schwan, S., Grajal, A., \& Lewalter, D. (2014). Understanding and engagement in places of science experience: Science museums, science centers, zoos, and aquariums. Educational Psychologist, 49(2), 70-85. https://doi.org/10.1080/00461520.2014.917588

Schreiber, J.B., Pekarik, A.J., Hanemann, N., Doering, Z., \& Lee, A.J. (2013). Understanding visitor engagement and behaviors. The Journal of Educational Research, 106(6), 462-468. https://doi.org/10.1080/00220671.2013.833011

Smith, L., Livingstone, A., \& Thomas, E. (2019). Advancing the social psychology of rapid societal change. British Journal of Social Psychology, 58(1), 33-44. https://doi.org/10.1111/bjso.12292

Teo, T. (2011). Reconstructing the critique of ideology: A critical-hermeneutic and psychological outline. Annual Review of Critical Psychology, 9, 20-27.

Teo, T. (2015). Are psychological "ethics codes" morally oblique? Journal of Theoretical and Philosophical Psychology, 35(2), 78. 78-89. https://doi.org/10.1037/a0038944

Tolan, P., Ross, K., Arkin, N., Godine, N., \& Clark, E. (2016). Toward an integrated approach to positive development: Implications for intervention. Applied Developmental Science, 20(3), 214-236. https://doi.org/10.1080/10888691.2016.1146080

Vygotsky, L.S. (1978). Mind in society: The development of higher psychological processes. Cambridge, MA: Harvard University Press.

Wilson, L., Bryant, W., Reynolds, F., \& Lawson, J. (2015). Therapeutic outcomes in a museum? "You don't get them by aiming for them." How a focus on arts participation promotes inclusion and well-being. Arts \& Health, 7(3), 202-215. https://doi.org/10.1080/17533015.2015.1046891

Original manuscript received August 08, 2019

Revised manuscript accepted November 01, 2019

First published online December 25, 2019

To cite this article: Bahia, S., Nogueira, J. (2019). The Importance of Communicating Psychological Concepts in Educational Contexts: a Portuguese Exhibition. Psychology in Russia: State of the Art, 12(4), 118-134. DOI: 10.11621/pir.2019.0407 